\title{
Análise da Participação de Meninas e Mulheres no Ensino Médio em Informática do Instituto Federal de Brasília
}

\author{
Sylvana Karla S. L. Santos ${ }^{1}$ \\ ${ }^{1}$ Instituto Federal de Brasília - Campus Brasília \\ sylkarla@gmail.com
}

\begin{abstract}
This article aims to characterize the presence of girls and women in an integrated high school course in computer science at the Federal Institute of Brasilia. The research is exploratory with data collection through a questionnaire with the participation of 21 students enrolled in the course. The results show that the participants consider the quality of the course to be relevant and believe in employability upon completion. However, they ponder prejudice on the part of family and colleagues during the course.
\end{abstract}

Resumo. Este artigo tem como objetivo caracterizar a presença de meninas e mulheres em um curso de ensino médio integrado em informática do Instituto Federal de Brasília. A pesquisa é exploratória com coleta dos dados por meio de questionário que contou com a participação de 21 alunas matriculadas no curso. Os resultados mostram que as participantes consideram relevante a qualidade do curso e acreditam na empregabilidade com a conclusão. Ponderam, no entanto, preconceito por parte da família e dos colegas durante o curso.

\section{Introdução}

A presença das mulheres na ciência vem sendo uma constante em pesquisas recentes que buscam verificar a participação e a produção científica deste grupo, bem como direcionar o "desenvolvimento de políticas científicas de incentivo e valorização feminina na ciência" [Tuesta et al. 2019 p. 37].

Alguns estudos buscam investigar quanti e qualitativamente fatores que podem levar tanto ao ingresso quanto à desistência deste público em cursos das áreas tecnológicas da Rede Federal, seja na formação continuada em cursos relacionados à programação e robótica [Santos et al. 2016] como em cursos técnicos de ensino médio na área de informática [Pereira et al 2020], e apontam para um número reduzido de mulheres nas turmas dos cursos ligados a fatores que remetem ao abandono do curso e à falta de estímulo para prosseguir.

De forma cultural, ainda persiste uma ideologia de separação de atividades que são frequentemente designadas, desde a infância, para um ou outro gênero e que costumam enfatizar o lado frágil das meninas, reservando a estas atividades de cuidado e afeto, enquanto que para os meninos é reforçado o lado bruto e também intelectual ao brindá-los com objetos de caráter mais técnico, como jogos ${ }^{1}$. Acrescenta-se a isso a ausência de citação de mulheres que fizeram parte da história da computação e de descobertas científicas, de forma geral.

\footnotetext{
1 Progra $\{\mathrm{m}\}$ aria. Por que o machismo cria barreiras para as mulheres na tecnologia. Disponível em: https://www.programaria.org/especiais/mulheres-tecnologia/ Acesso em: 14 mar. 2021
} 
Como principal justificativa, a pesquisa pressupõe que há uma discrepância evidente na quantidade de estudantes do gênero feminino em detrimento aos estudantes do gênero masculino em cursos das áreas de tecnologia [Santana et al. 2017]. Infere-se que há uma discriminação que se propaga historicamente, na qual é posta a divisão de que há profissões definidas para mulheres e outras para homens.

Neste cenário, percebe-se que, embora as mulheres possam fazer escolhas e ingressar em cursos das áreas de tecnologia, elas continuam sofrendo preconceitos por estarem em locais majoritariamente ocupados por homens, mesmo que consigam se destacar intelectualmente neste meio. Assim, é importante promover a discussão de gênero no contexto do ensino técnico de nível médio da Rede Federal de Educação Profissional. O objetivo da pesquisa é obter informações acerca das estudantes do curso Técnico de Ensino Médio Integrado (EMI) em Informática do Instituto Federal de Brasília (IFB) e caracterizar a presença de meninas e mulheres no curso.

Após esta contextualização, traz-se a Seção 2 que apresenta o local de realização da pesquisa, que é o IFB. Na Seção 3 é descrita a metodologia e evidenciado o instrumento de coleta desenvolvido e aplicado. A Seção 4 trata dos resultados obtidos e, finalmente, a Seção 5 detalha algumas considerações sobre o estudo.

\section{A oferta de cursos técnicos pelo IFB}

O Instituto Federal de Brasília (IFB) foi criado pela Lei $n^{0}$ 11.892/2008 e é uma das 64 instituições da Rede Federal de Educação Profissional e Tecnológica (EPT), que totaliza 661 unidades presentes nas 27 unidades da federação [MEC 2020]. No Distrito Federal (DF), o IFB possui 10 campi sendo um na capital e os demais em regiões administrativas.

A oferta de cursos pelo IFB é distribuída em Formação Inicial e Continuada (FIC), técnico integrado ao nível médio, técnico concomitante e técnico subsequente, além de cursos de nível superior em licenciatura, bacharelado e tecnólogo e pós-graduação com especialização. O nível médio integrado é ofertado com 18 cursos, distribuídos em 10 eixos tecnológicos e que totalizou, em 2020, mais de 3 mil estudantes [IFB 2020].

A partir de uma análise breve dos dados das matrículas no EMI Informática em 2020, percebe-se que a presença de meninas e mulheres é menor e equivale a um terço, em média, se comparada ao sexo masculino, o que reforça a tendência de indicadores publicados em trabalhos recentemente publicados [Ribeiro e Maciel 2020].

\section{Metodologia}

A pesquisa, de caráter exploratório, tem abordagem quantitativa e qualitativa, pois tem interesse em interpretar ações e relações humanas [Kauark e Manhães 2010]. Possui duas etapas, sendo a primeira identificar o quantitativo de alunas matriculadas no curso técnico EMI Informática no campus Brasília do IFB em 2020. Dados da matrícula em 2020 apontaram um quantitativo de 63 meninas e mulheres no referido curso, sendo este considerado o universo para fins deste trabalho, caracterizadas por adolescentes com idades entre 12 e 18 anos.

A segunda etapa da pesquisa busca caracterizar a presença dessas alunas no referido curso. Para isso, foi elaborado um instrumento de coleta de dados, aplicado de forma remota com o auxílio de um formulário eletrônico. Diante do ensino remote, o público foi alcançado pelo envio de um convite por mensagens pelo Whatsapp e pelo 
Direct do Instagram. Antes de responder às questões, as participantes tiveram que fazer o aceite do Termo de Consentimento Livre e Esclarecido no formulário, o qual esclarece a participação voluntária e anônima à pesquisa de caráter estritamente acadêmico.

O instrumento de coleta contou com 15 questões objetivas e uma questão aberta para que a participante pudesse deixar comentários. Buscou-se abordar, a partir das questões, um levantamento sóciodemográfico para identificar idade e renda mensal familiar, investigar motivações para a escolha, permanência e desempenho no curso, a influência da família e dos amigos e planos futuros para a carreira. A coleta foi realizada entre os dias 29 de agosto e 19 de setembro de 2020 e alcançou 21 participantes, o que equivale a $34,4 \%$ do total de matriculadas no curso.

A seguir, são apresentados os dados coletados e os resultados alcançados.

\section{Resultados e Discussões}

As questões iniciais buscaram caracterizar o perfil sociodemográfico das participantes. A primeira pergunta teve o objetivo de identificar como a participante se identificava quanto ao gênero e todas responderam "feminino" (100\%). As demais opções possíveis foram "outro" e "prefiro não dizer".

A idade das participantes ficou distribuída com relativa uniformidade entre as possibilidades, mostrando predominância para as que possuem até 15 anos (29\%) e de estudantes com 16 anos (33\%), que estão nos primeiros dois anos do curso. A maioria afirmou que reside com um grupo familiar de cinco ou mais pessoas $(38 \%)$ e com 4 pessoas (34\%). Estes números apontam para famílias numerosas.

No contexto da renda familiar, mais da metade das participantes afirmaram que a renda familiar é de até dois salários mínimos (52\%). Esse dado, enquanto maioria, corrobora com o perfil já conhecido do estudante que ingressa nos cursos do IFB, segundo informações da Assistência Estudantil, e reforça a necessidade de ações afirmativas para a reserva de vagas pelo sorteio, bem como de políticas públicas para transpor questões de vulnerabilidade social dos estudantes.

A principal motivação para frequentar o curso foi a qualidade, seguida da possibilidade de conseguir emprego. Na sequência, a gratuidade do curso foi também destacada além da importância e do status da área ou do curso. Percebe-se que a área da tecnologia é ainda um ponto forte para a maioria das alunas que respondeu, estando de acordo com o trabalho de Ribeiro e Maciel [2020].

Ter sido admitida pelo sorteio é um dos pontos relevantes para frequenter o curso, seguido do fato gostar da área de informática e ter recebido indicações de conhecidos, ainda que em menor proporção. Isso pode refletir que a formação na área técnica integrada no IFB é mais pertinente se comparada ao ensino médio regular, por exemplo.

A característica de morar próximo ao campus foi apontada como pouco relevante pelas participantes. É de conhecimento da pesquisadora que algumas alunas residem há mais de $30 \mathrm{~km}$ de distância do campus Brasília, inclusive em cidades localizadas na região do entorno do DF, o que demonstra possivelmente uma afinidade pelo curso.

Para avaliar o desempenho das alunas durante o curso, foram lançados questionamentos quanto à percepção individual, coletiva e com relação aos professores. 
Dois terços das alunas, ou seja, 14 afirmaram que gostam muito do curso. Por outro lado, esse mesmo quantitativo disse que sente dificuldades.

Para a maioria das respondentes, foi apontado que existe um pouco preconceito de colegas (13) e de professores (14) com relação à presença de meninas e mulheres no curso. Infere-se desse sentimento a existência de barreiras relacionadas à capacidade de prosseguir bem como ao machismo, considerando o curso de maioria masculina, fato que pode dificultar a permanência das estudantes no curso [Aires et al. 2018]. Para contornar essa situação, é importante estar atento ao acolhimento das meninas e mulheres que ingressam no curso e na área da tecnologia para reforçar um constante empoderamento [Santana et al 2017].

O apoio da família com relação ao curso foi apontado por 16, enquanto que quase a totalidade delas pondera sentir pouco preconceito (19). A maioria das alunas disse enfrentar poucas ou algumas barreiras, que podem estar relacionadas com o ceticismo de que o curso escolhido não é para elas, como um reflexo do ingresso feminino em uma carreira tida como masculina. $O$ apoio dos colegas com relação a curso teve 11 concordâncias, número próximo àquelas que indicam sentir um pouco de preconceito dos colegas de curso, percepção semelhante à que foi apontada com relação à família.

A maior parte das alunas indicou que enfrentam barreiras em um grau regular ou pequeno $(90 \%)$. Tais indicadores refletem um nível alto de incômodo no ambiente escolar, em um cenário semelhante ao familiar, o que remete à existência de um preconceito velado ou despercebido.

Apenas 6 delas afirmaram que estão cumprindo dependência em disciplinas (29\%), o que pode refletir a necessidade de reforço para alcançar competências e habilidades. Considerando a dedicação exigida pelo curso em conteúdos de ciências exatas, apenas 2 afirmaram que já repetiram o ano letivo, aproximadamente, $2 \%$ participantes.

As três últimas questões foram voltadas à projeção do futuro profissional após a formação no curso e 15 participantes disseram que pretendem trabalhar na área do curso técnico após concluírem (71\%). Apenas oito das alunas declararam que desejam seguir a carreira universitária na mesma área do curso técnico (38\%). A maioria (67\%) acredita que terá um futuro profissional de sucesso na área do curso técnico, crença confirmada por 14 das participantes.

A seguir, serão pontuadas algumas considerações sobre esta investigação e indicadas sugestões para a continuidade com trabalhos futuros.

\section{Considerações Finais}

A pesquisa buscou caracterizar a presença de meninas e mulheres no curso técnico em informática integrado ao ensino médio no IFB. A expectativa inicial da coleta dos dados era alcançar, pelo menos, 50 participantes, a fim de obter uma amostra mais abrangente. Embora essa previsão não tenha sido cumprida, considera-se que as respostas demonstram um recorte inicial que pode ser ampliado futuramente, que pode ser justificada pelo contexto da pandemia do COVID-19 e o distanciamento físico diante do atual modelo de ensino remoto do curso.

A partir da análise dos dados, percebe-se que a maioria das alunas faz parte de famílias com mais de quatro pessoas, possuem renda familiar de até dois salários 
mínimos. Esse enredo demonstra a condição de vulnerabilidade da maioria do público atendido pelo IFB, reforça a necessidade de avaliar programas de assistência estudantil e ter uma equipe multidisciplinar para auxiliar e acompanhar o progresso das alunas.

De toda forma, a pesquisa não tem a pretensão de esgotar as discussões sobre o ingresso e a permanência de meninas e mulheres no referido curso, pois acredita-se que este trabalho serve como insumo para buscar novos questionamentos e proporcionar encaminhamentos a questões de gênero no IFB. Por isso, sugere-se dar continuidade à pesquisa para: (1) identificar projetos liderados por pesquisadoras e com a participação de bolsistas ou voluntárias que sejam estudantes do EMI no IFB; (2) verificar a produção científica de pesquisadoras, sejam docentes ou técnicas, em parceria com alunas do EMI no IFB; (3) investigar as dificuldades enfrentadas por pesquisadoras para a realização de pesquisas ou produção científica considerando fatores, como maternidade.

Por fim, destaca-se a recente criação do Núcleo de Gênero e Diversidade do IFB, sendo este responsável pelo desenvolvimento de ações voltadas às questões de gênero, direitos da mulher e da comunidade LGBTI+ no campus. Uma destas ações foi "Conheça uma Cientista", realizada a partir da página Meninas na Ciência do IFB no Instagram [@meninasnacienciaifb] e em comemoração ao Dia Internacional das Mulheres e Meninas na Ciência, em 11 de fevereiro.

\section{Referências}

Aires, J.; Mattos, G.; Oliveira, C.; Brito, A.; Aragão, A. F.; Alves, S.; Coelho, T.; Moreira, G. (2018) Barreiras que Impedem a Opção das Meninas pelas Ciências Exatas e Computação: Percepção de Alunas do Ensino Médio. In: Women In Information Technology, p. 1-5.

IFB (2020) Portal IFB em Números. Disponível em: www.ifbemnumeros.ifb.edu.br

Kauark, F. S.; Manhães, F. C.; Medeiros, C. H. M. (2010) Metodologia da pesquisa: Guia Prático. Itabuna, BA: Via Litterarum. [online]

Pereira, J. S.; Moura, L. R.; Coelho, N. M. A.; Montes, G. C.; Magesti, I. O.; Coelho, A. M. (2020) Uma Análise da Participação das Mulheres nos Cursos Técnico em Informática e Ciência da Computação do Instituto Federal do Sudeste de Minas Gerais. In: Women In Information Technology, p. 139-148.

Ribeiro, K. S. F. M.; Maciel, C. (2020) Fatores de Influência na Escolha pela Continuidade da Carreira em Computação pelas Estudantes de Ensino Médio Técnico em Informática. In: Women In Information Technology, p. 40-49.

Santana, T. S.; Assis, I. T. B.; Braga, R. B.; Louzada, N. C. (2017) A importância de atividades de empoderamento feminino como forma de minimizar a evasão das mulheres nos cursos de Tecnologia da Informação. In: Women In Information Technology, p. 1204-1207.

Santos, T. N.; Manenti, M. T.; Pozzebon, E.; Frigo, L. B. (2016) Incentivando meninas do ensino médio a ingressarem nas áreas tecnológicas com curso de programação e robótica. In: Women In Information Technology, p. 43-46.

Tuesta, E. F.; Digiampietri, L. A.; Delgado, K. V.; Martins, N. F. A. (2019) Análise da participação das mulheres na ciência: um estudo de caso da área de Ciências Exatas e da Terra no Brasil, Em Questão, 25(1), p.37-62. 